
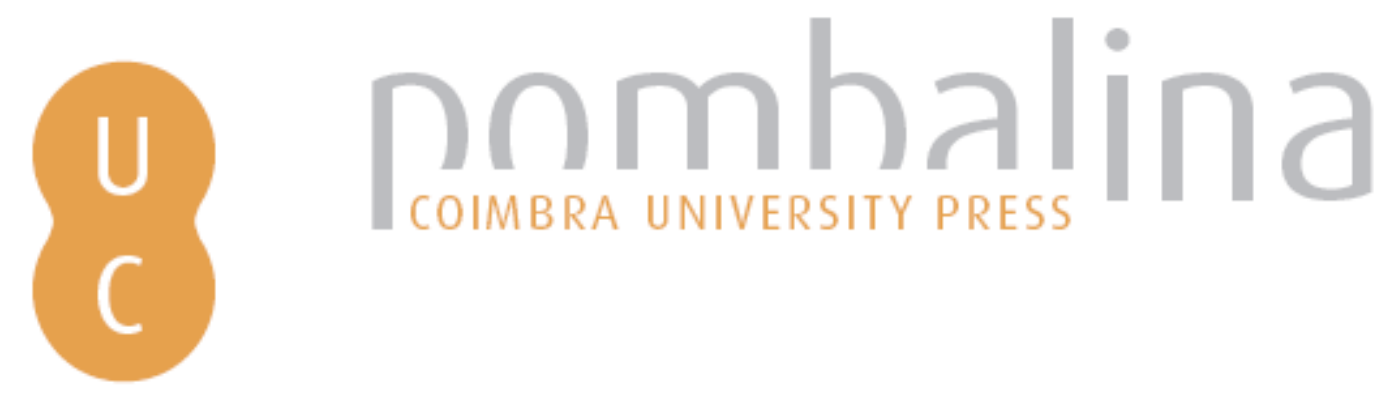

\title{
Lille: a dimensão cultural da água
}

Autor(es): $\quad$ Lemeiter, Richard, ed. lit.; Pinon, Julien

Publicado por: Imprensa da Universidade de Coimbra

URL persistente:

URI:http://hdl.handle.net/10316.2/39328

DOI:

DOI:http://dx.doi.org/10.14195/978-989-26-1025-2_13

Accessed : $\quad$ 26-Apr-2023 16:33:32

A navegação consulta e descarregamento dos títulos inseridos nas Bibliotecas Digitais UC Digitalis, UC Pombalina e UC Impactum, pressupõem a aceitação plena e sem reservas dos Termos e Condições de Uso destas Bibliotecas Digitais, disponíveis em https://digitalis.uc.pt/pt-pt/termos.

Conforme exposto nos referidos Termos e Condições de Uso, o descarregamento de títulos de acesso restrito requer uma licença válida de autorização devendo o utilizador aceder ao(s) documento(s) a partir de um endereço de IP da instituição detentora da supramencionada licença.

Ao utilizador é apenas permitido o descarregamento para uso pessoal, pelo que o emprego do(s) título(s) descarregado(s) para outro fim, designadamente comercial, carece de autorização do respetivo autor ou editor da obra.

Na medida em que todas as obras da UC Digitalis se encontram protegidas pelo Código do Direito de Autor e Direitos Conexos e demais legislação aplicável, toda a cópia, parcial ou total, deste documento, nos casos em que é legalmente admitida, deverá conter ou fazer-se acompanhar por este aviso. 


\section{A DIMENSÃO CULTURALDA AGUA}

\section{$\cos 8$}

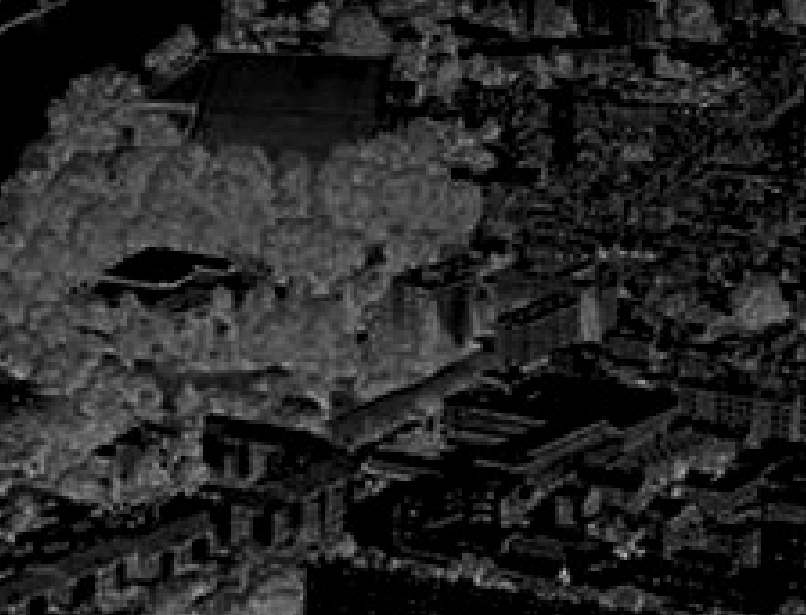

\author{
$\min 2$ \\ a.s.
}

RICHARD LEMEITER (Coordenador)
TULIEN PINON

artigy-

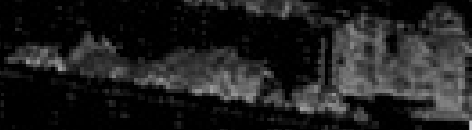

Definições em que ños apoiamos neste programa: ys

Água $=\mathrm{a}$ água sob todas as suas formas, todas as águas (subPatrimónio = bem herança comum de uma coletividade de um

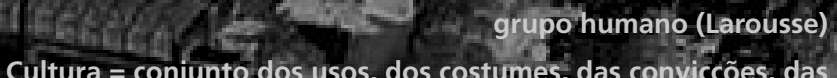
Cultura $=$ conjunto dos usos, dos costumes, das conviçções, das manifestaçôes art ísticas, religiosas, intelectuais que definem $\mathrm{e}$ distinguem um grupo, uma sociedade (Larousse)

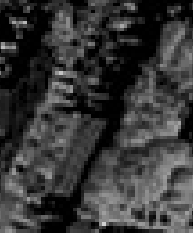

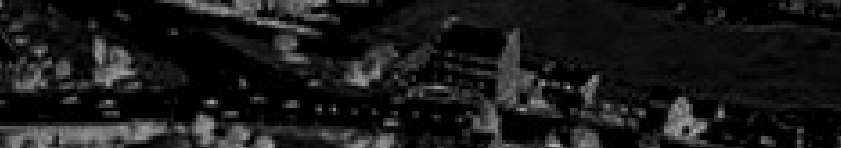

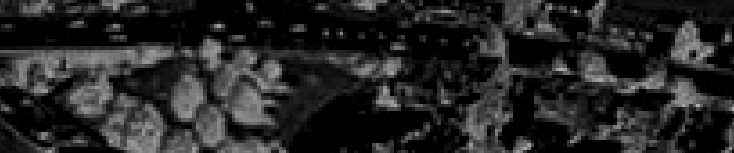

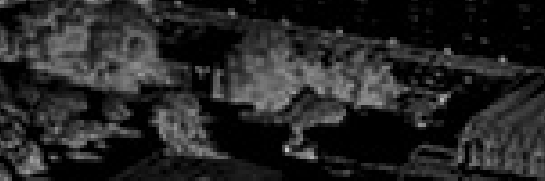

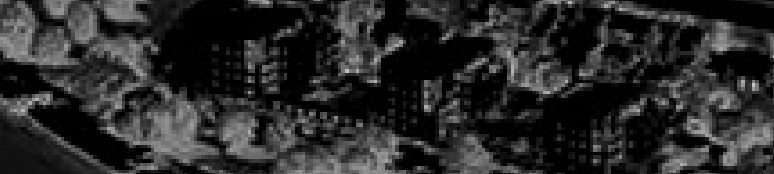
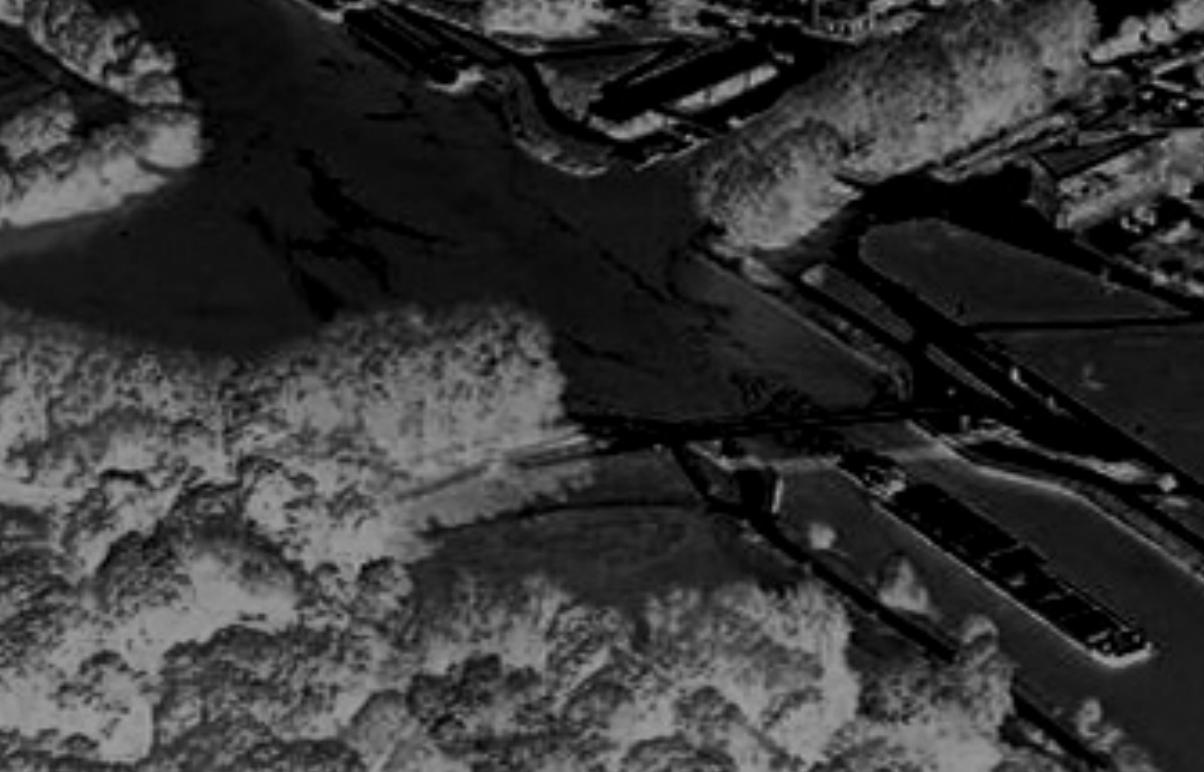


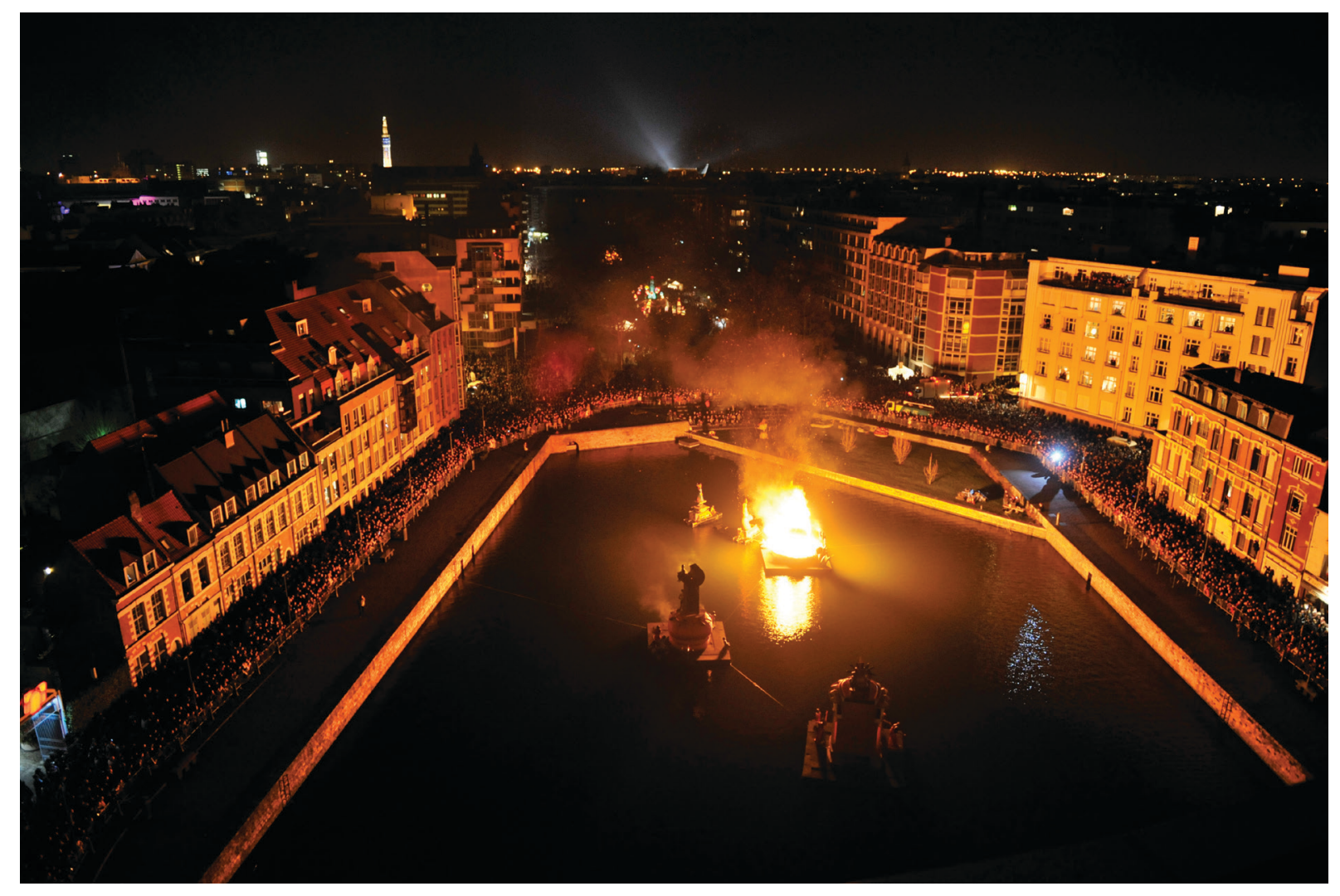

O Cais do Wault em 2004 - Cerimónias das Fallas 


\section{A PROBLEMÁTICA DA CIDADE DE LILLE}

Como estabelecer a dimensão cultural do rio Deûle para fazer dele um espaço mais utilizado, mais vivo?

A água pode ser abordada sob diferentes ângulos (estético, lúdico, patrimonial, cultural, ecológico, etc.), é um instrumento potencial de desenvolvimento.

Numerosas coletividades francesas e europeias comprometem-se atualmente com projetos de reconquista dos seus cursos de água e canais e isto, a escalas variáveis, que vão do simples cais de uma aldeia, ao projeto intermunicipal (Plano Azul Metropolitano da Metrópole de Lille), distrital, regional (île de France - Canal de l'Ourcq) ou mesmo transnacional (Estrasburgo).

Esta reconquista das margens passa, com frequência, pela encenação da água e a criação de espaços públicos que acolhem manifestações populares, culturais, dinamizações (margens do Sena transformadas em zonas pedonais, em Paris). Estas duas ações constituem frequentemente as próprias bases das políticas de retorno à água empreendidas em muitas cidades.

Assim se justapõem diferentes maneiras de animar os cursos de água urbanos. Às festividades ligadas a heranças do passado, vêm juntar-se acontecimentos de dinamização cultural, espetáculos que têm uma dimensão estética (encenação: iluminação, nascentes) ou uma dimensão mais prática e usual (lazeres, descanso, jogos de água).

Esta patrimonialização dos recursos ligados à água não tem uma dimensão museológica e ajuda a pensar a água como suporte vital, um lugar do qual depende um certo número de ecossistemas, mas também a fonte de uma dimensão cultural para fazer desse lugar um espaço mais utilizado, mais vivo.

No momento em que, em Lille, emerge o desejo de reencontrar as suas raízes aquáticas, o compromisso da cidade com um projeto europeu sobre a temática da água como suporte de acontecimentos culturais, abre pois uma via para a emergência de uma estratégia cultural de apropriação da água.

\section{O procedimento}

Este projeto europeu fez evoluir a nossa visão. Tomámos consciência da importância do Humano, do papel e do lugar dos habitantes num projeto urbano, para que o enxerto pegue e o projeto possa funcionar.

Até maio de 2012, o procedimento de Lille neste projeto europeu estava centrado na dimensão cultural (o património, os acontecimentos, a arquitetura) e num único lugar: a estação de água.

Desde junho de 2012, no final do workshop, a dinâmica elegeu o Humano como eixo ao longo de toda a linha do rio: a fita azul.

\section{O lugar do Humano, dos habitantes no projeto urbano}

Parece necessário voltar a colocar o Humano, os habitantes e os usos no centro da noção de património. Um projeto urbano deve ser concebido para os habitantes da cidade. 
Aquando da criação de um projeto de ordenamento, constata-se, com frequência, uma grande contestação por parte dos habitantes. É, frequentemente, devido ao facto de os habitantes não conhecerem o projeto e de imaginarem coisas erradas, levando-os a medos infundados.

Para evitar que isso aconteça, convém levar a cabo as seguintes ações:

- Informar, explicar as intenções do projeto;

- Concertar, pedir a opinião dos habitantes;

- Fazer visitar o lugar, pôr em situação física ou virtual (ateliers, imaginação, role plays);

- Ter em conta a memória e o sentimento dos habitantes relativamente ao projeto;

Um ordenamento deve constituir-se como um meio e não um fim em si mesmo.

Estes procedimentos vão ajudar os habitantes a compreender os desafios e os objetivos do projeto e, consequentemente, permitir-Ihes formar uma opinião com conhecimento de causa.

Convém lembrar que a vertente sociológica do SDEL revelou uma forte sensibilidade dos habitantes relativamente à temática da água e a grande maturidade da sua reflexão sobre o tema. Existe uma procura real de informação no que diz respeito à água e aos projetos do município de Lille ligados ao rio Deûle. Antes da realização dos projetos, parece pois fundamental comunicar amplamente os conteúdos do quadro aqui estabelecido no âmbito destes projetos, para que a sua finalidade e a sua justificação económica sejam bem compreendidas.

\section{A aplicação da problemática}

O rio Deûle e os seus antigos canais marcaram profundamente a história e influenciaram o desenho da cidade de Lille. Desse ponto de vista, constituem um património, um bem transmitido e a transmitir, cuja reabilitação e conquista estão doravante em causa. Convém assim valorizar o património de ontem e criar o património de amanhã. As potencialidades económicas, sociais e ambientais do Deûle estão ainda insuficientemente exploradas na globalidade do seu percurso, em contracorrente com a crescente procura dos cidadãos relativamente à natureza.

Atendendo à estreita relação entre o curso do rio e o curso da cidade, a possibilidade de utilizar o seu potencial identitário e jogar com o imaginário dos lugares é uma oportunidade para fazer nascer um novo laço afetivo entre a cidade e o seu rio bem como para melhorar o quadro de vida e a imagem da cidade. Constituindo uma estrutura em rede, as vias de água oferecem igualmente a oportunidade de Lille e a sua região apreenderem um território mais vasto e iniciar uma reflexão à escala da bacia hidrográfica.

Um projeto de ordenamento da via de água ligando cultura e urbanismo é para Lille a oportunidade de valorizar a sua imagem, ao mesmo tempo que procura colocar-se ao nível dos patamares europeus em termos de valorização da água como acontece em Amsterdão, Londres, Leipzig, nas cidades do vale do Ruhr, em Oslo, Copenhaga...

A reflexão sobre as potencialidades de dinamização do curso do rio Deûle deve ir de par com a condução dos projetos urbanos. A festa é aliás um bom revelador do "bom viver em conjunto". A "festivalização do ordenamento" é um tema particularmente interessante que deve ligar-se ao conceito de cidade intensa. 


\section{O trabalho dos estudantes}

Um atelier de urbanismo ou workshop foi levado a cabo em Lille durante uma semana no mês de maio de 2012. Quatro equipas internacionais de 6 a 7 estudantes - supervisionados por um professor de um dos quatro países - fizeram propostas de ordenamento de um local de cada país do programa europeu. Tratava-se das seguintes cidades: Braila na Roménia (Danúbio), Coimbra em Portugal (Mondego), Comacchio na Itália (no delta do rio Pó) e por fim Lille (Deûle). O local selecionado para Lille era a da estação de água, situado a cavalo entre as municipalidades de Lille e de Lomme.

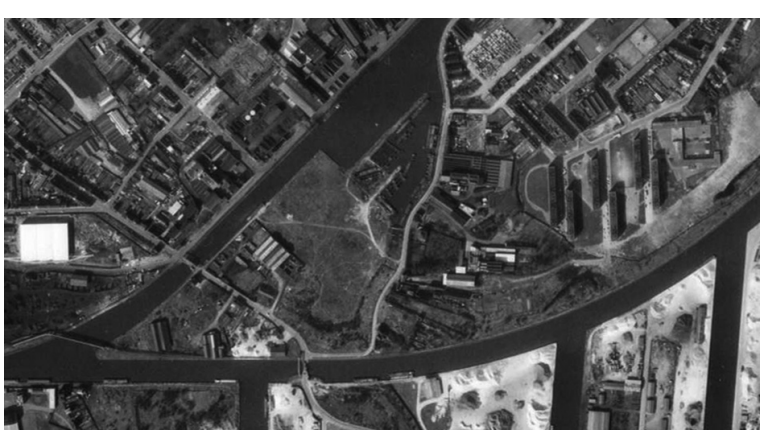

1969

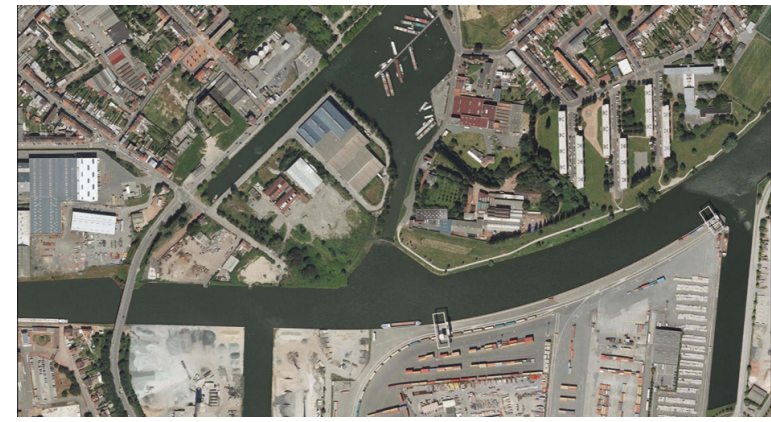

2012

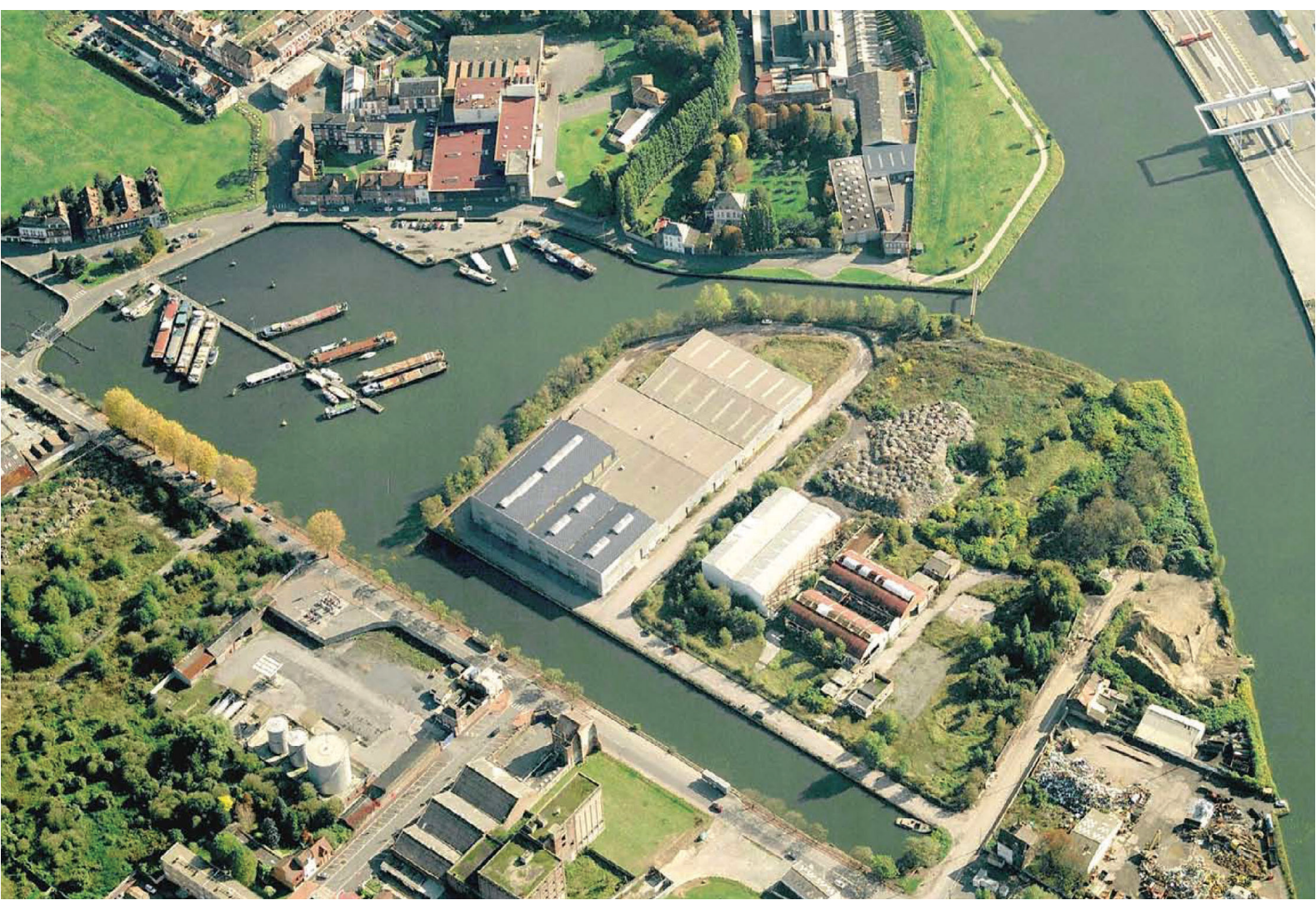

Estação de água e quase ilha Boschetti - 2012 
$3=2 x=3 x$

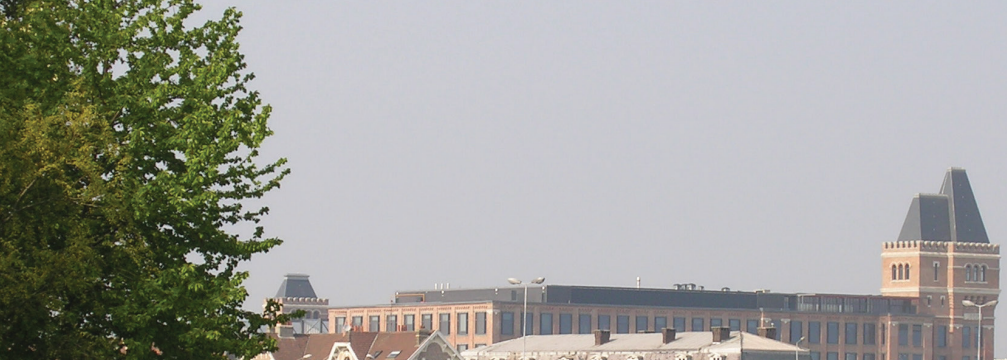

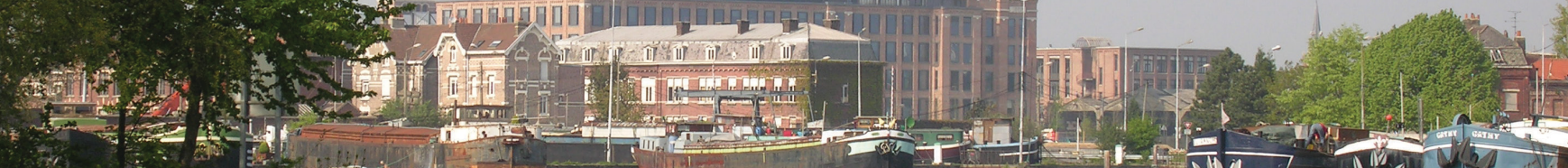

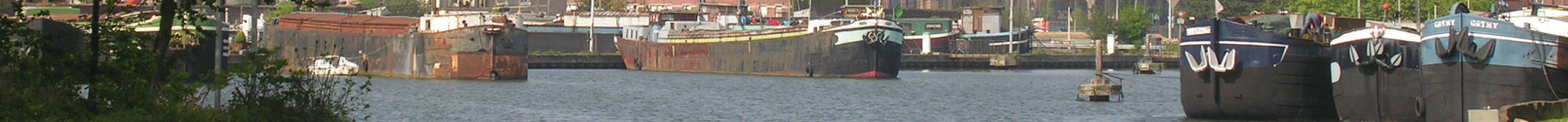

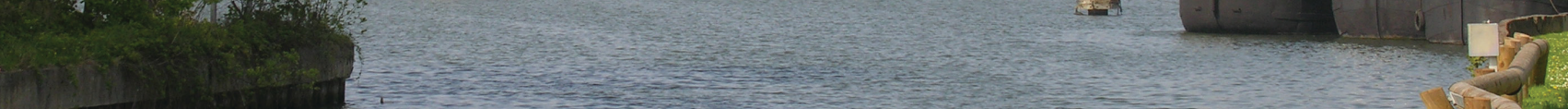
20.

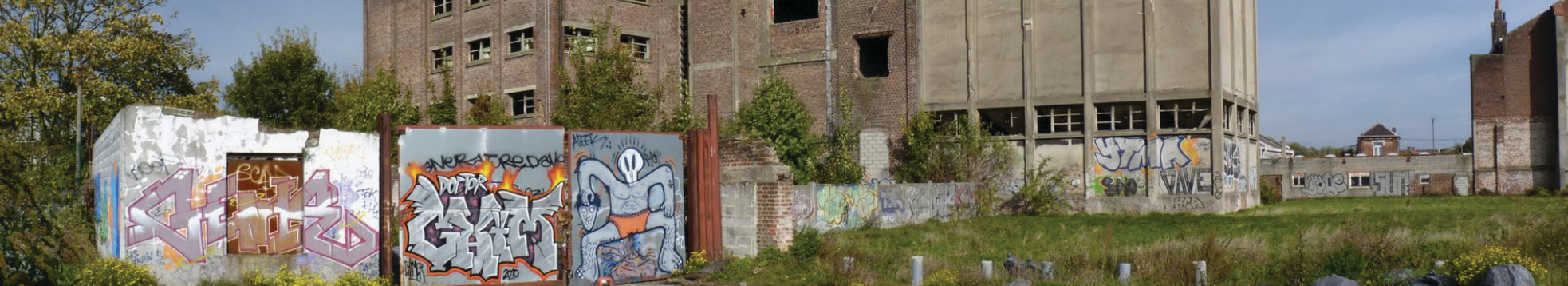
4

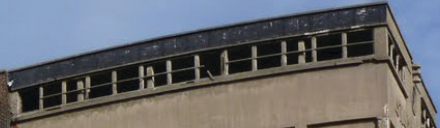

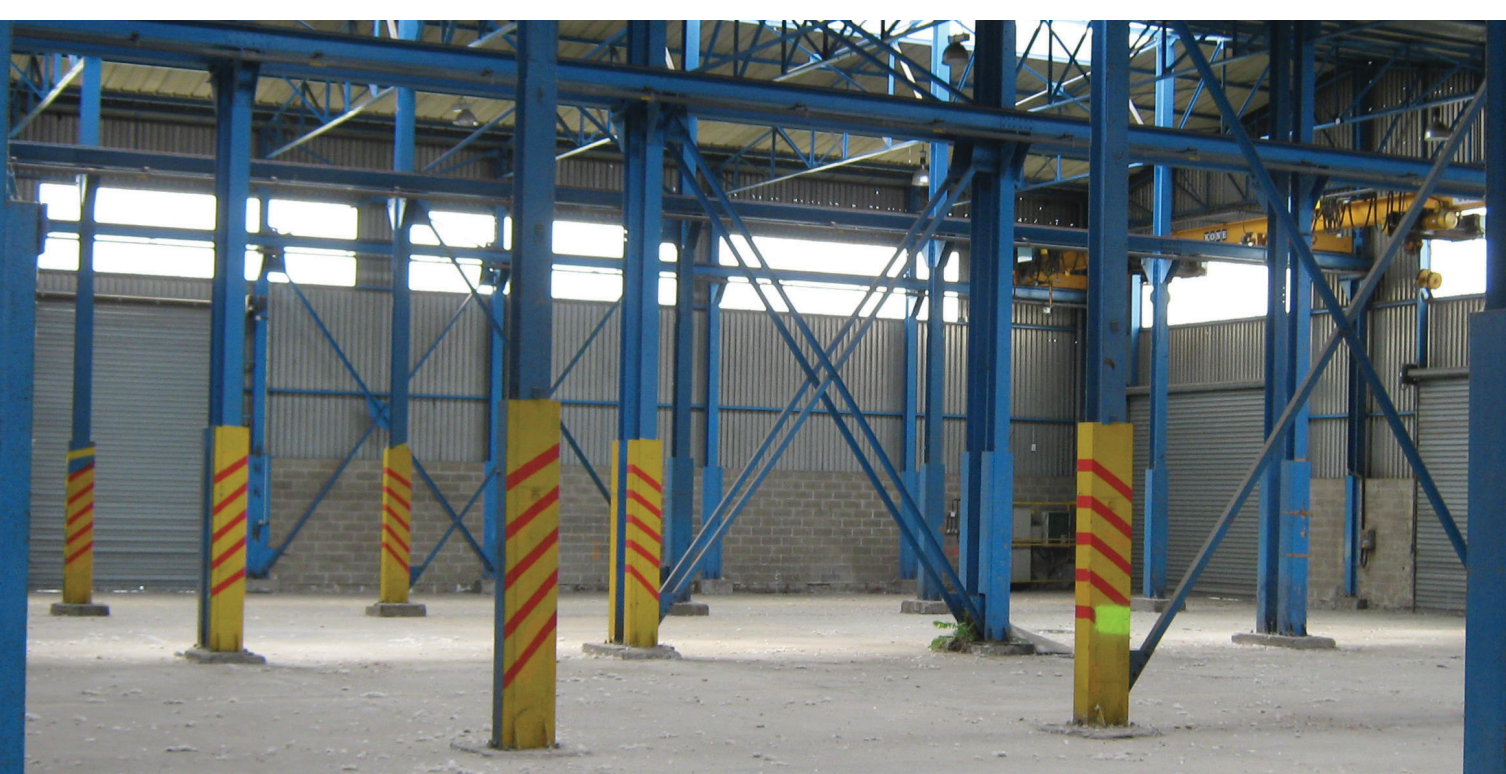

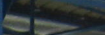

$>$

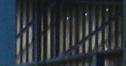

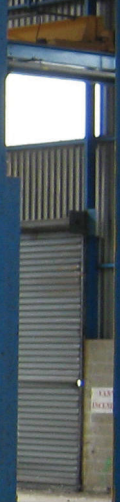




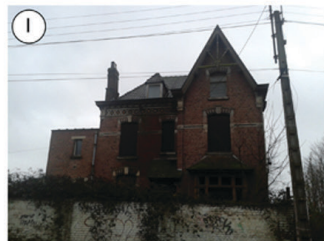

(2)
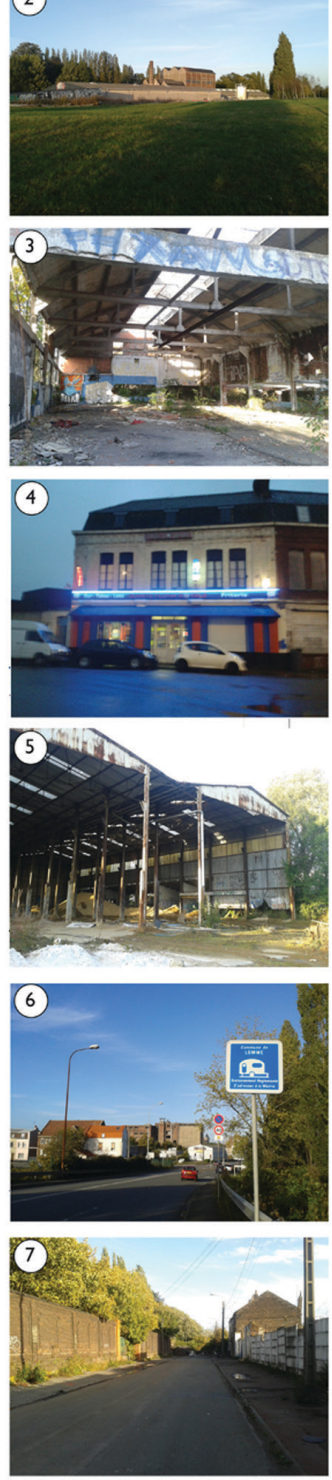

(8)

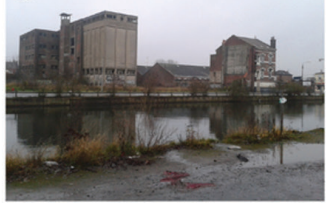

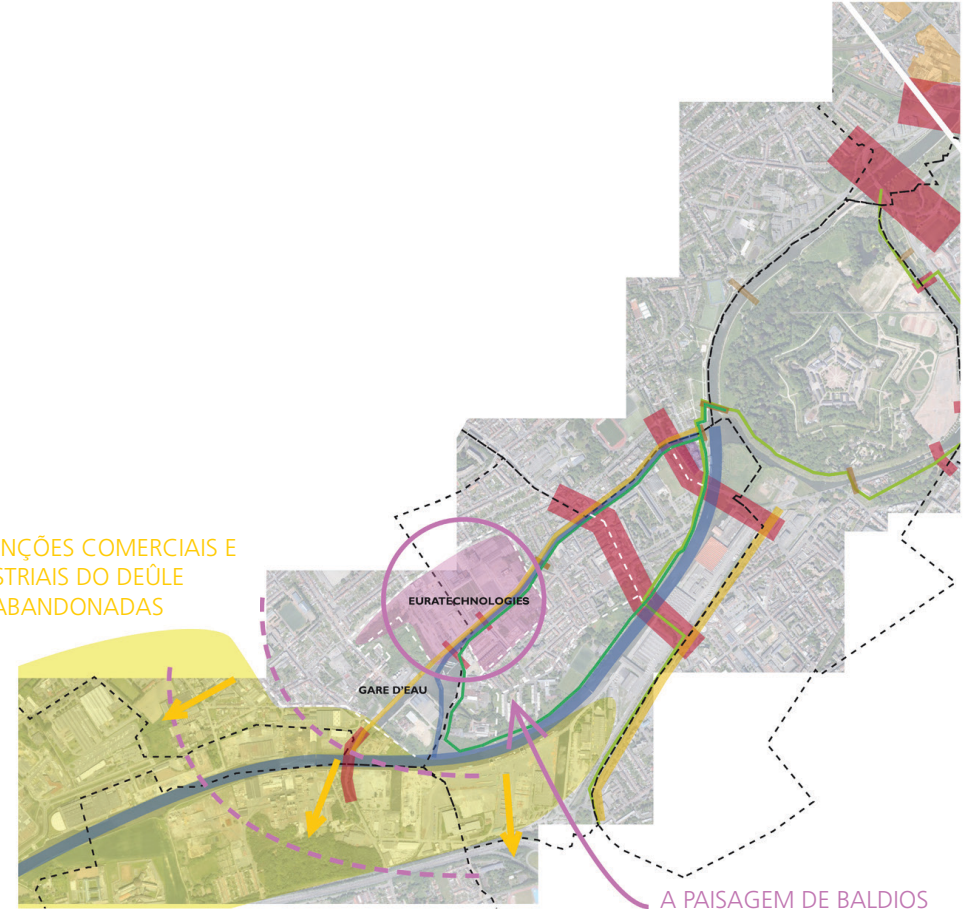

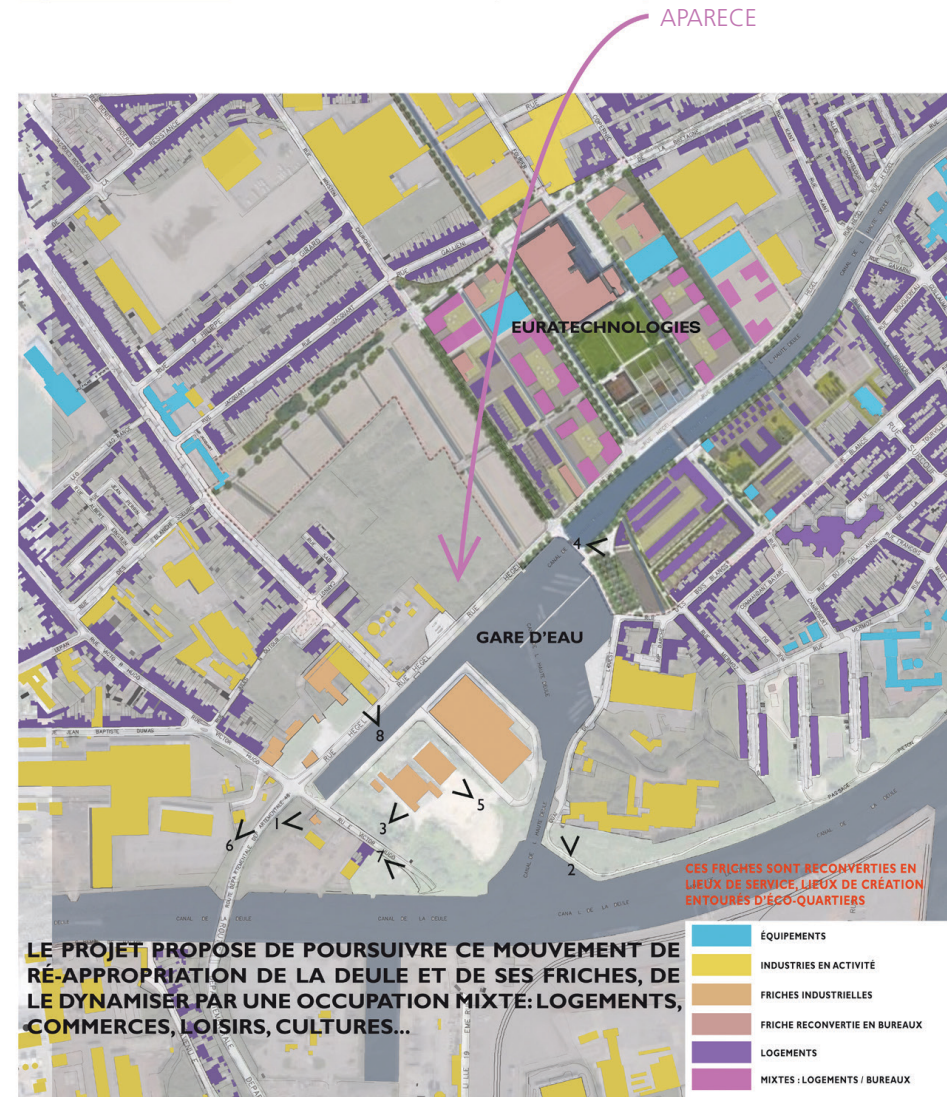

O PROJETO PROPÕE CONTINUAR O MOVIMENTO DE

REAPROPRIAÇÃO DO DEÛLE E DOS SEUS BALDIOS, DINAMIZÁ-LO PARA UMA OCUPAC ÃO MISTA DE ALOJAMENTOS, COMÉRCIOS, LAZERES, CULTURA... 


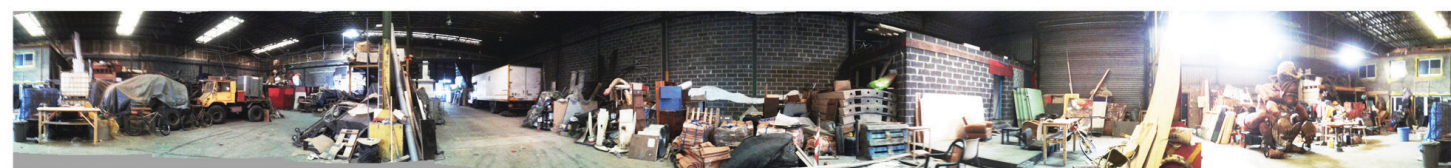

\section{CENÁRIO I - PROJETO}

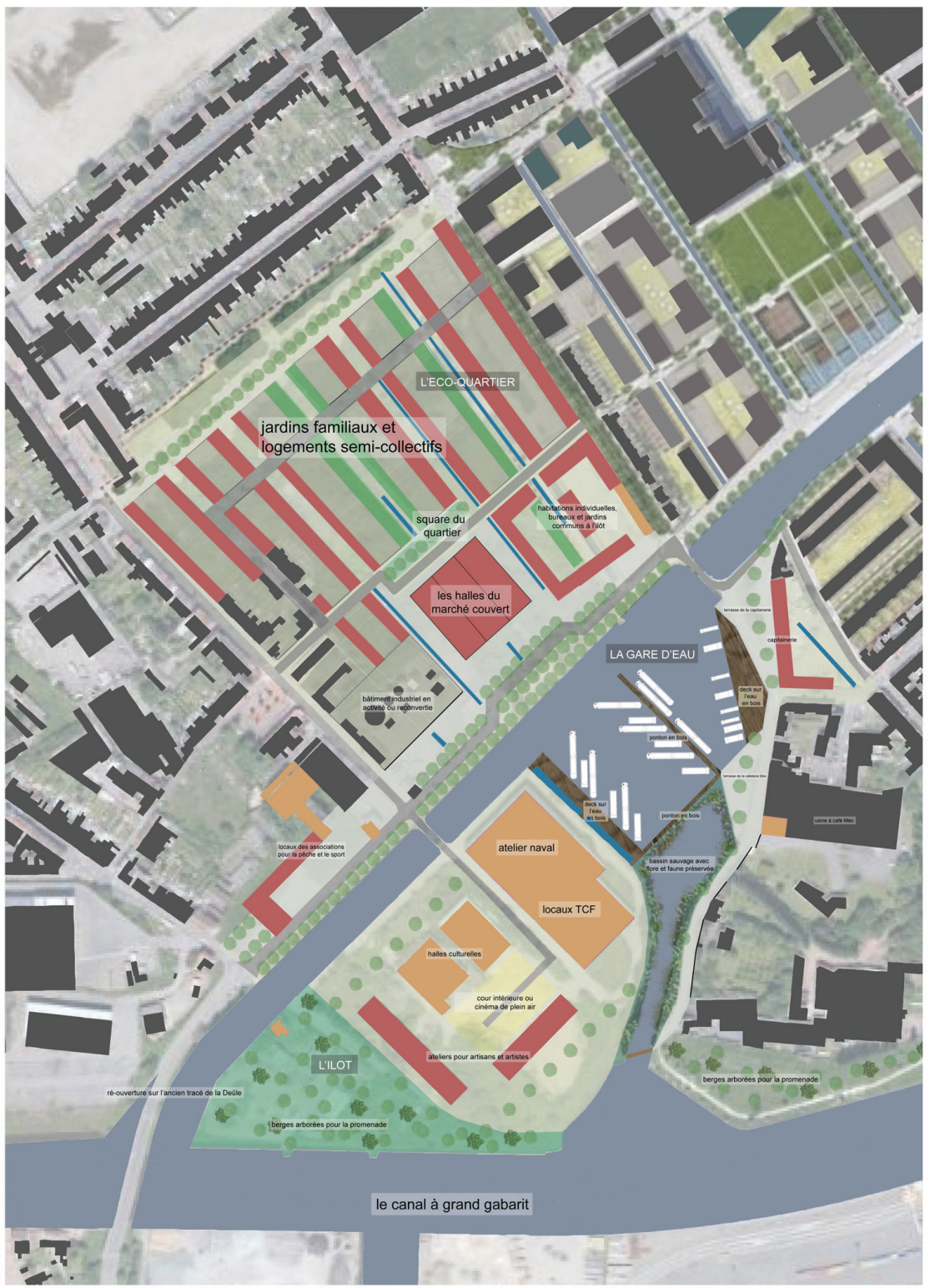

\section{IMAGESDERÉFÉRENCES}
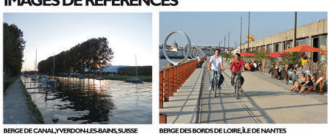

\section{SCHEMADIRECTEUR INITIAL}

GERME\&JAM-200I

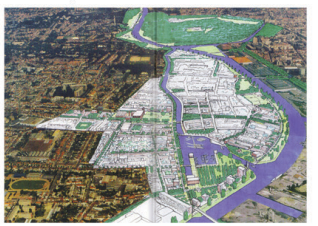

UMA MISTURA DE OCUPAÇÃO

DE USOS

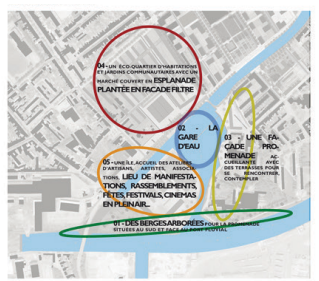

CRIAÇÃO DE 3 FACHADAS ANIMADAS PARA DELIMITAR A ESTAÇÃ̃ DE ÁGUA

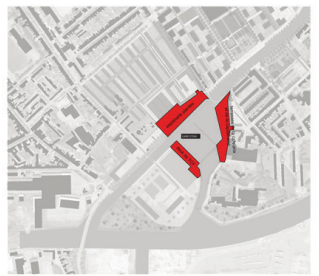

TIPOLOGIAS DAS DIFERENTES PEÇAS DE ÁGUA E DAS SUAS MARGENS

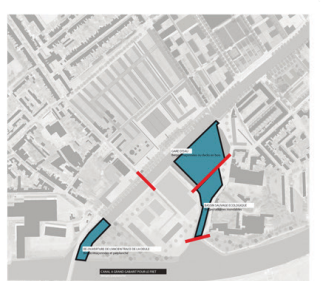



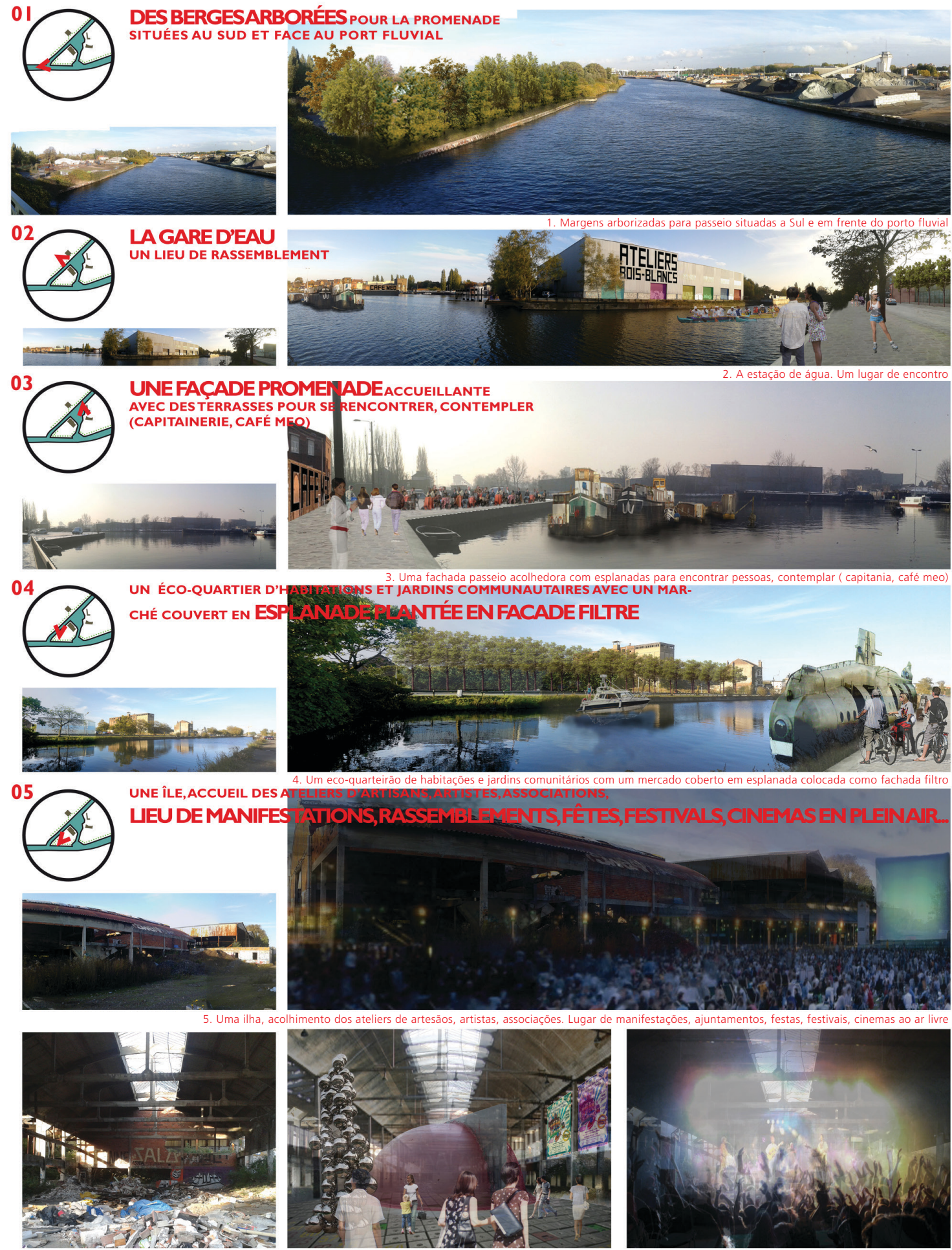


\section{Na sequência do workshop de maio 2012 em Lille}

Um estudo urbano foi lançado por Lille Metrópole e pela cidade de Lille. Uma equipa pluridisciplinar foi assim encarregue de realizar um diagnóstico e propostas de ordenamento para este sítio.

Paralelamente, os estudantes da Escola Nacional Superior de Arquitetura e Paisagens de Lille prolongaram o trabalho levado anteriormente a cabo pelos estudantes do Instituto de Ordenamento e Urbanismo de Lille, alargando o perímetro de reflexão ao conjunto da Metrópole de Lille.

\section{Vale do Marque}
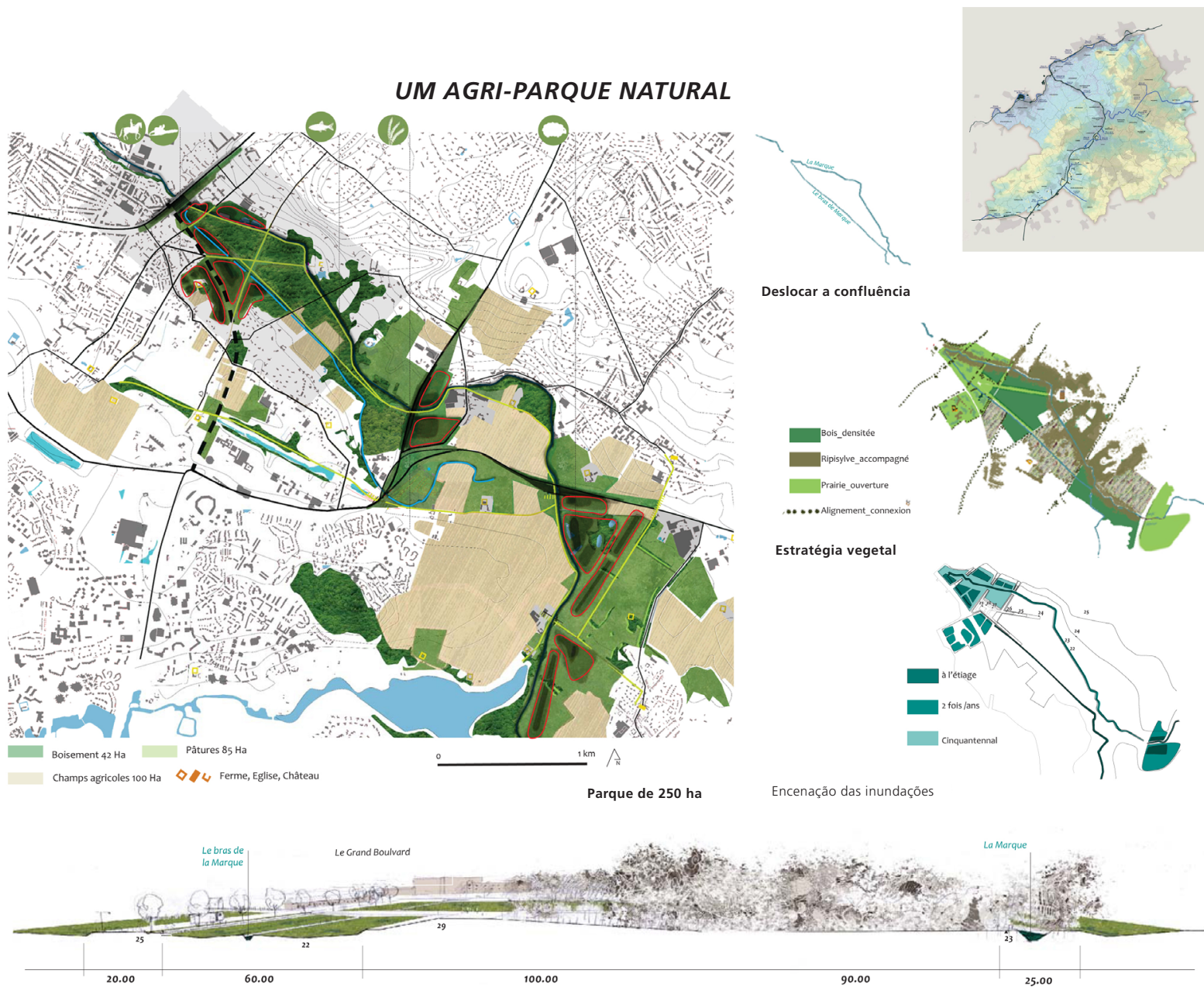

O equilíbrio aterro / terraplanagem dá forma ao parque 


\section{Canal de Seclin}

TURISMO RURAL - AgROTURISMO

O turismo rural é uma forma alternativa de turismo em meio rural, designadamente junto dos agricultores (agriturismo ou agroturismo) ou dos viticultores

(enoturismo) mas também entre as pessoas que habitam no campo ainda que năo vivam da terra.

\section{$1+\frac{1}{3}$}

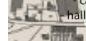

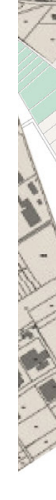

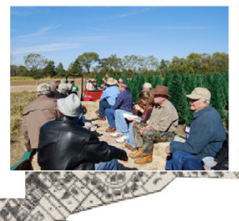
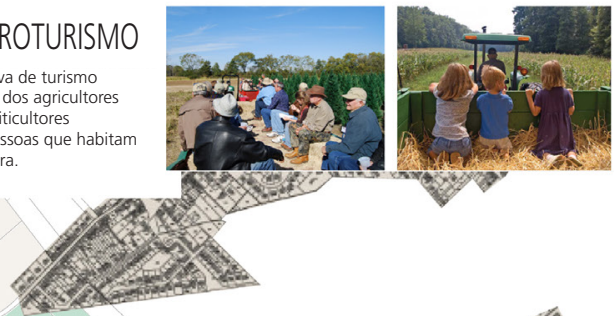

3. $\rightarrow$

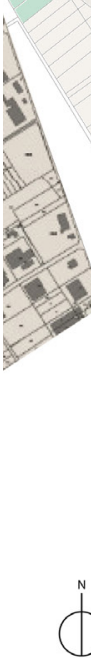

N
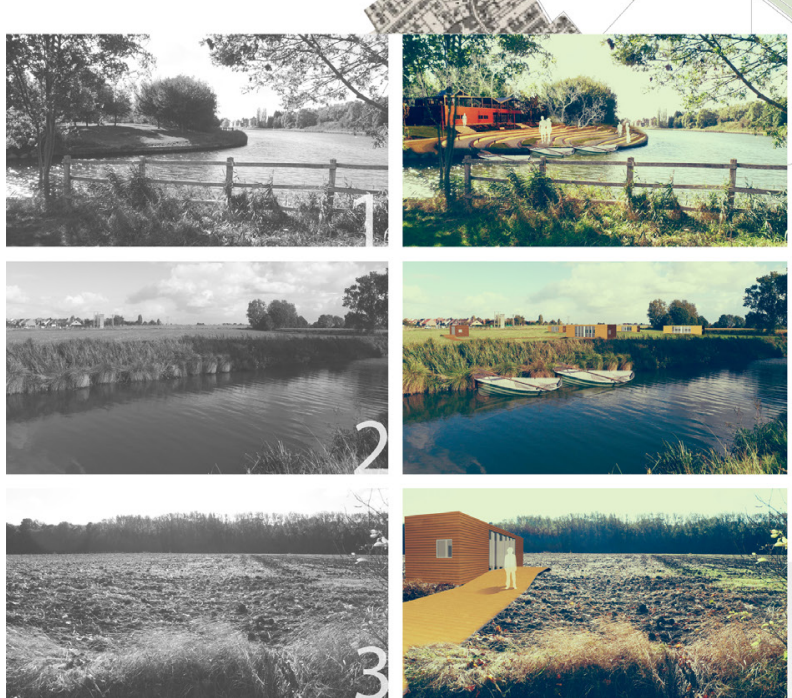
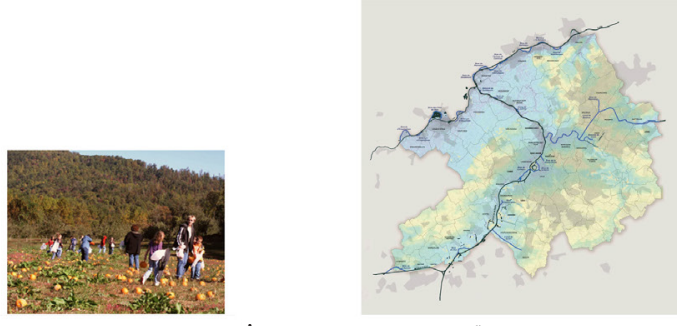

AS FORÇAS DE ORGANIZAÇĀO

beneficiando da presença da Casa Pouillerie, aumentar a reder de agroturismo:

descobrir o território mergulhando nele;

alargar as dimensōes de tempo e de espaço;

ligar o território da agricultura com o lugar de Seclin utilizando as embarcações;

garantir a acessibilidade do pavilhão pelo canal;

desenvolver o território que perdeu a função industrial a partir de uma estratégia hibrida

abrir o território à cidade, mas com menos elementos mais instrumentos;

reforçar a permanência temporária nos pavilhões - cultivando o tereno e usando a água.
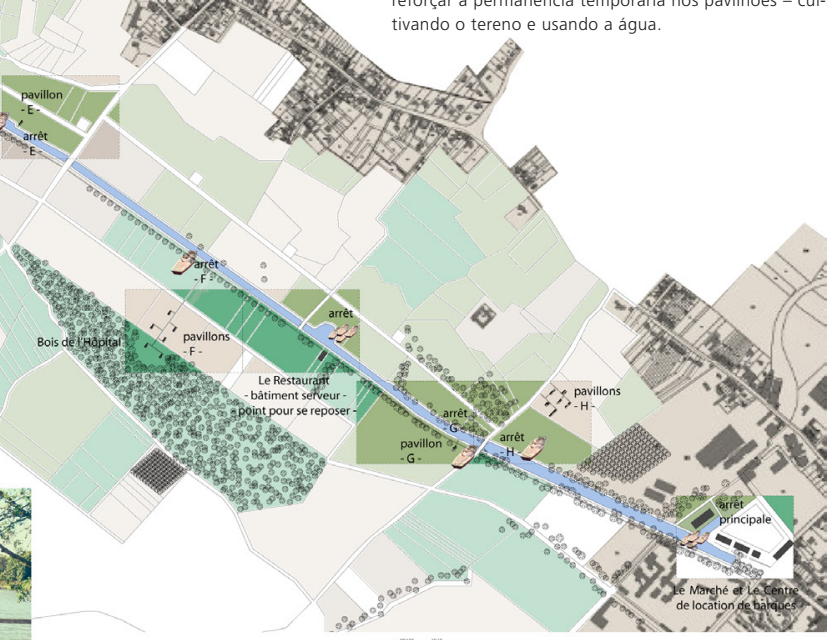

Pavillon - Module
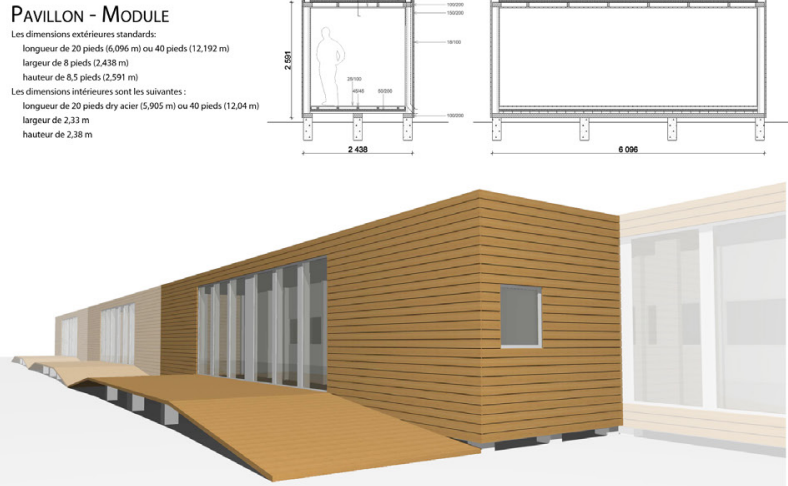


\section{Abrir, recuar no zoom}

Da complementaridade à transversalidade das abordagens nos projetos de reabilitação da água na cidade.

A fim de levar a cabo uma ação coerente, convém retroceder no zoom, ter uma reflexão à escala metropolitana. É preciso trabalhar em rede, com os outros municípios e instituições públicas. É igualmente interessante e útil apoiar-se nas associações. O trabalho levado a cabo ao longo deste projeto europeu reconfortou-nos na ideia de que não é possível funcionar sozinhos. É preciso pôr os lugares, os meios e os projetos em rede, em comum. Com efeito é interessante conduzir ações multi-lugares, no conjunto do rio.

É preciso refletir em termos de complementaridade e não de concorrência. Este trabalho em rede, o facto de trabalhar em cooperação com outras cidades deve fazer-se no próprio território mas também à escala internacional.

Convém aplicar o procedimento deste seminário a outros projetos, em outros domínios (o social, a investigação, a inovação, etc.). Paradoxalmente, falamos da água mas com um olhar de terrestres.

Não seria interessante modificar o nosso ponto de vista e olhar para o nosso património a partir da água?
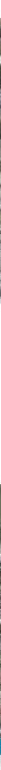

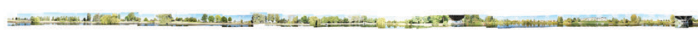

Bosque Branco
Lambersat
Baixo Deûle 


\section{Baixo Deûle}

Água lúdica e artes fluviais

Margens para prática desportiva e natureza na cidade

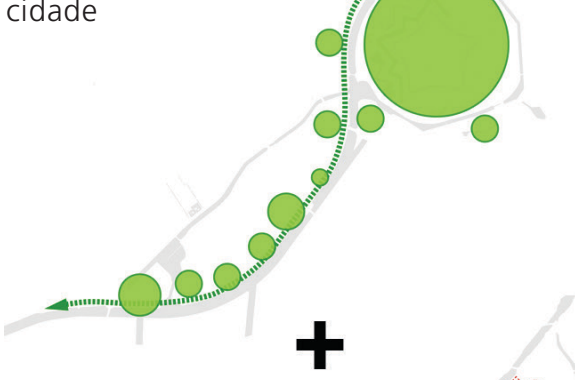

Bairro-Canal patrimonial, habitado e festivo

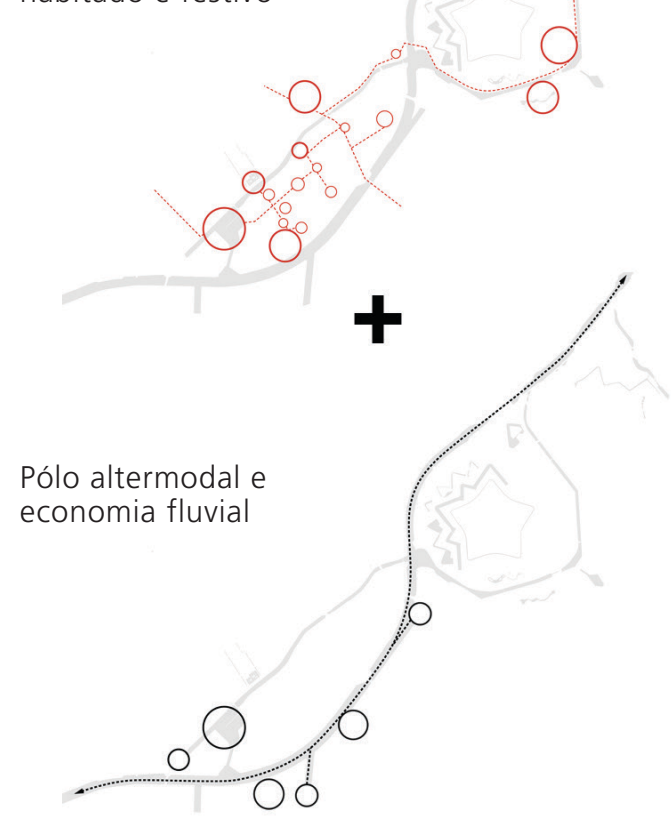

\section{Conclusão}

Alargamento da problemática passando:

- Do património à cultura;

- Do ordenamento ao Humano;

- De um lugar único ao conjunto do rio;

- Necessidade de trabalhar em rede;

- Tomada em consideração dos habitantes.

Este tipo de seminário europeu representa uma oportunidade para todos. Esta cooperação, o facto de não mais trabalhar sozinhos, permite abrir a reflexão e a ação.

Abertura geográfica:

A fim de realizar estes objetivos e estes projetos, torna-se necessário trabalhar com os municípios vizinhos tendo presente o que se faz noutros lugares em França e na Europa.

Abertura temática:

Aplicámos as problemáticas dos outros países (biodiversidade, património arquitetónico, desenvolvimento económico) ao nosso espaço e à nossa reflexão sobre o território de Lille.

Quatro problemáticas que convergem para a estação de água e determinam dois níveis de intervenção:

- Com pinceladas sucessivas ao longo do percurso;

- Com uma ação massiva focando a estação de água e a península de Bosquetti. 


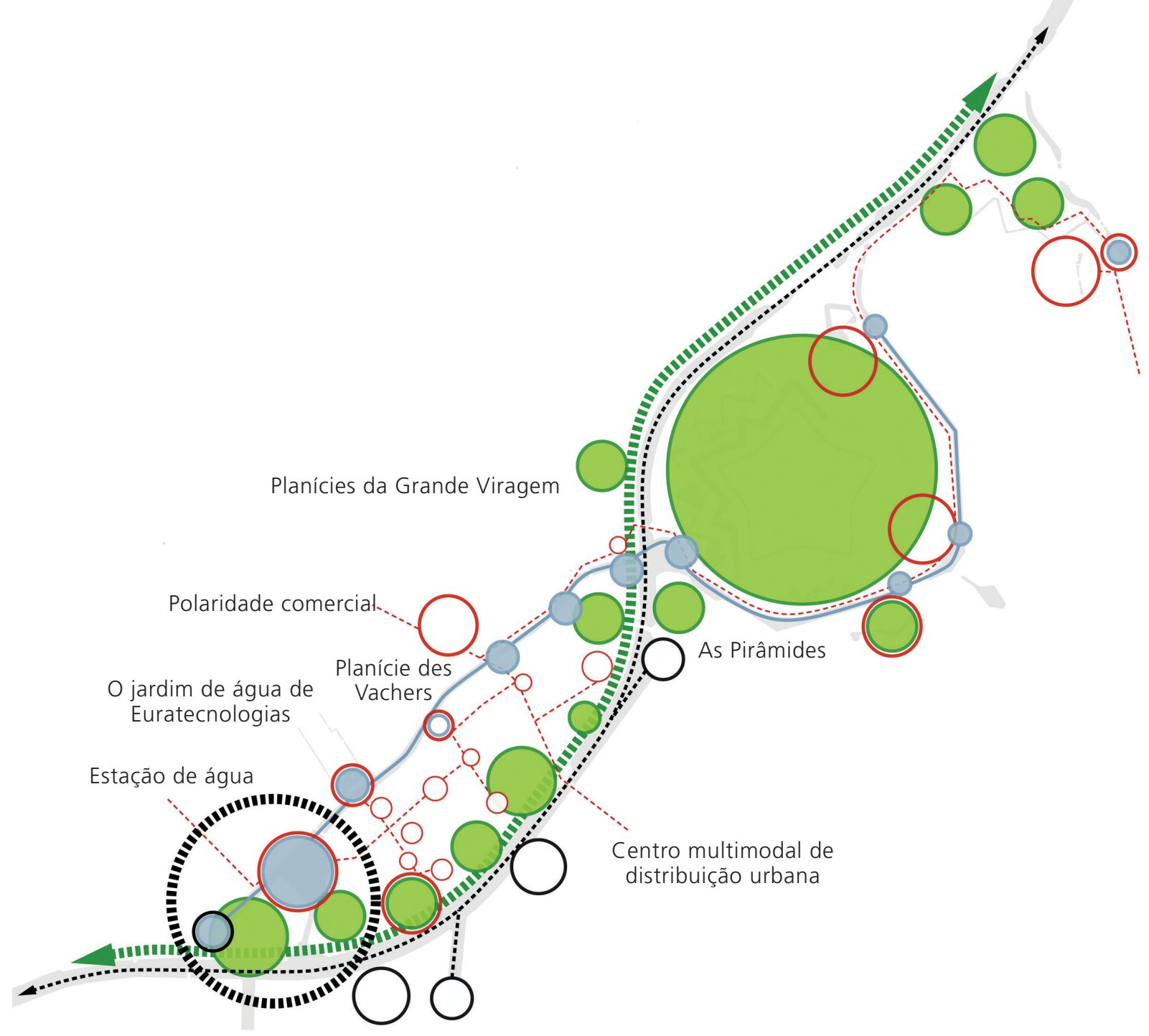

